\title{
Encephalitis Presenting as Acute Schizophrenia
}

\author{
P. C. MISRA, G. G. HAY
}

due to an allergic response, possibly to a viral infection, though not a direct viral invasion of the brain. By early December, though not taking any phenothiazine drugs, he had developed def-

\section{Summary}

Three patients developed symptoms suggestive of acute schizophrenia. In each case there were no abnormal neurological findings on admission to hospital. Within a few days clinical evidence of encephalitis became apparent, and appropriate treatment was given. Only one patient made a full recovery.

\section{Introduction}

It has long been known that cases of encephalitis may present with symptoms of psychiatric disturbance (Jelliffe, 1925; Hall, 1929). In most of these patients consciousness is clouded and positive neurological findings are present, so that no diagnostic difficulty arises, at least in differentiating them from cases of acute functional psychosis (Weinstein et al., 1955). Economo (1931), however, writing of encephalitis lethargica, mentioned that such patients could present without evidence of impairment of consciousness and without physical signs, and indeed that the mental changes might be the only symptoms of the disease. He emphasized the initial similarity of these cases to acute schizophrenia or mania, and described how the catatonia of dementia praecox could be simulated.

Because of the comparative rarity of such cases we think it of interest to record those of three patients who within nine months were admitted to the same psychiatric unit with a provisional diagnosis of schizophrenia.

\section{Case 1}

A grammar-school boy of 18 was sent home from school on 10 October 1967 because of "odd" behaviour. When seen two days later he was excited, overactive, restless, and talking continually in a disconnected fashion about a variety of topics. There was no flight of ideas or elation and no evidence of clouding of consciousness. The family history was negative for nervous or mental illness.

He was admitted to hospital under Section 25 of the Mental Health Act. At that time, 12 October, he was apyrexial and there were no abnormal physical findings. On the ward he became aggressive and showed definite catatonic features. At times he was mute, but on other occasion's he spoke clearly and was correctly orientated A provisional diagnosis of acute schizophrenia was made.

On 14 October the physical findings were checked and the right plantar response was thought to be equivocal. Two days later both plantars were extensor and abdominal reflexes on the left were diminished. Lumbar puncture showed nothing abnormal. Next day his temperature rose to $100^{\circ} \mathrm{F}\left(37.8^{\circ} \mathrm{C}\right)$ and his mental state became that of a subacute delirium. He spent the time muttering and shouting and remained very restless, particularly at night. E.E.G. was reported a's abnormal, with reduction in the alpha rhythm and slow activity in all areas.

A diagnosis of acute encephalitis was made and treatment with corticotrophin was started on the basis that the illness might be

Bolton District General Hospital, Farnworth, Bolton, Lancs P. C. MISRA, M.B., B.SC., Senior House Officer in Psychiatry G. G. HAY, M.D., D.P.M., Consultant Psychiatrist (Present address: 'Withington Hospital, Manchester M20 8LR) inite extrapyramidal features with cogwheel rigidity in all limbs, expressionless facies, and monotonous voice, and at the time of writing he presented the picture of postencephalitic Parkinsonism.

\section{Case 2}

A married woman aged 45, a part-time clerk, was admitted under Section 25 of the Mental Health Act in April 1968. There was a three-week history of depression and irritability, and for two weeks she had without reason accused her husband of infidelity, writing obscene letters to him. The night before she came into hospital she had stayed up talking continually about her husband's supposed sex crimes. Family history was negative for nervous or mental illness.

On admission she appeared alert and there was no evidence of clouding of consciousness. She complained that people at work had been purposely avoiding her and that they made signs and winked at each other when she was near them. She thought that she had somehow been drugged, and that people in the office could "take" her thoughts out of her mind. She had been hallucinated, hearing voices projected in space talking about her in the third person. On physical examination there were no abnormal findings, and a provisional diagnosis of acute schizophrenia was made.

Three days later she became pyrexial $\left(101^{\circ} \mathrm{F} ; 38.3^{\circ} \mathrm{C}\right)$ and when examined her knee and ankle jerks were absent, with the left plantar response extensor. Lumbar puncture showed nothing abnormal, but E.E.G. showed a moderate disorganization throughout with a general excess of symmetrical fast activity. She became extremely ill and later developed auricular fibrillation and congestive heart failure. A diagnosis of encephalitis with complicating myocarditis was made and she was treated accordingly. She made a gradual and complete recovery.

\section{Case 3}

A mill worker aged 19 was admitted on 27 June 1968 under Section 25 of the Mental Health Act. He had been taken into custody earlier that day by the police for trying to break into a van and had been noted by them to be grossly disurbed mentally. He gave his name initially as Clarke Gable and said he wa's travelling to California; later he said he was from Mars.

On admission he was difficult to examine, being aggressive and negativistic. He was auditorily hallucinated and admitted to "thought insertion." $\mathrm{He}$ was, however, correctly orientated and there was no clouding of consciousness. Physical examination was negative. His parents said he had been behaving in a peculiar fashion at home for two days before admission. There was a family history of schizophrenia (maternal aunt), and a provisional diagnosis of acute schizophrenia was made.

Two days later he developed, a temperature of $99.2^{\circ} \mathrm{F}$ $\left(37 \cdot 3^{\circ} \mathrm{C}\right)$ and was drowsy at times, but nothing physically abnormal was found until four days after admission, when the right abdominal reflexes were noted to be diminished and both plantars were extensor. Lumbar puncture showed nothing abnormal, but E.E.G. showed a moderate excess of theta activity maximal in the temporal leads. He became more somnolent, and treatment with corticotrophin was begun, the diagnosis of an encephalitis having been made.

Over the following day's he developed additional neurological signs in that the pupils became dilated and did not react to light or convergence and ankle clonus developed on the right side. He became very restless, particularly at night, but then improved, and about one month after his admission all the neurological signs had 
regressed. His mental state, however, remained unchanged, and as it was considered possible that the encephalitis could have precipitated schizophrenia in a genetically predisposed individual a course of electric convulsion therapy was given, with definite improvement. At the time of writing (September 1970) he showed features of a chronic schizophrenic defect state.

\section{Discussion}

The occurrence of schizophrenia-like states in encephalitis is of great theoretical interest and there has been much discussion on the significance of such a presentation. It has been postulated that the patient must be genetically loaded for schizophrenia and that the illness has released a constitutional predisposition (Bumke, 1924). However, a recent review of the whole topic of schizophrenia-like psychoses associated with organic disorders of the central nervous system, including encephalitis of various types, showed that such cases usually occur in patients without a genetic loading for schizophrenia (Davison and Bagley, 1969). Only one of our three cases had a positive family history for mental illness. It would seem, therefore, that in these schizophrenia-like cases the encephalitis is usually of direct aetiological significance rather than merely a precipitating factor.

Of more practical relevance, in view of the importance of early diagnosis in encephalitis, is the fact that all these cases were admitted to a psychiatric unit with a provisional diagnosis of acute schizophrenia and with clinical pictures initially indistinguishable from the latter. They are recorded as a reminder of a possible presentation of encephalitis.

\section{References}

Bumke, O. (1924). Klinische Wochenschrift, 3, 437.

Davison, $\dot{K}$., and Bagley, C. R. (1969). In Current Problems in Neuropsychiatry, ed. R. N. Herrington, p. 113. London, Royal Medico-Psychological try, ed. R. N. Herrington,
Association Publications.

von Economo, C. (1931). Encephalitis Lethargica: Its Sequelae and Treatment. Translated by K. O. Newman. London, Oxford University Press.

Hall, S. B. (1929). British Medical Fournal, 1, 444

Jelliffe, S. E. (1925). American fournal of Psychiatry, 6, 413.

Weinstein, E. A., Linn, L., and Kahn, R. L. (1955). Fournal of the Mount Sinai Hospital, 21, 341 .

\section{PRELIMINARY COMMUNICATIONS}

\section{Xylose Test: Effect of Aspirin and Indomethacin}

\author{
M. J. KENDALL, SHEILA NUTTER \\ C. F. HAWKINS
}

British Medical fournal, 1971, 1, 533-536

\begin{abstract}
Summary
The xylose test was used to assess the effect of drugs on intestinal absorption. Both aspirin and indomethacin reduced the urinary output of xylose. By giving xylose intravenously as well as orally it was found that aspirin had a parenteral effect, probably impairing renal function, whereas indomethacin depressed intestinal absorption.
\end{abstract}

\section{Introduction}

Drugs such as neomycin (Jacobson, Prior, and Faloon, 1960; Jacobson, Chodos, and Faloon, 1960) and phenformin (Stowers and Brewsher, 1969) affect intestinal absorption and reduce xylose excretion. Both aspirin and indomethacin cause dyspepsia, but their effect on intestinal function in man is unknown. Experiments on animals suggest that they might interfere with absorption since both drugs inhibit the active transport of an amino-acid (Levy, Angelino, and Matsuzawa, 1967) and salicylates affect the passage of glucose (Smith, 1958) across isolated intestinal preparations. Drugs may also modify renal function. Aspirin may cause analgesic nephro-

Gastrointestinal Laboratory, Queen Elizabeth Hospital, Birmingham 15 M. I. KENDALL, M.R.C.P., Research Fellow

SHEILA NUTTER, A.I.M.L.T., Research Technician

C. F. HAWKINS, M.D., F.R.C.P., Consultant Physician pathy (Nanra and Kincaid-Smith, 1970), though acute renal effects have not been described.

The xylose test is a useful way of assessing intestinal function, the site of its absorption being the jejunum. Low values may, however, be due either to malabsorption or to renal impairment, though in the latter the excretion of intravenously administered xylose will also be low (Kendall, 1970). We have used oral and intravenous xylose to study the effects of aspirin and indomethacin on absorption and excretion.

\section{Patients and Methods}

The oral test was performed with a 5-g dose of D-xylose and an initial two-hour and subsequent three-hour collection of urine as suggested by Sammons et al. (1967). For the intravenous test the same dose is given as $50 \mathrm{ml}$ of $10 \%$ solution; the urine is then collected as for the oral test to give two-hour and total five-hour excretions (Kendall, 1970). Excretion of xylose in the urine decreases with age, but this was not a factor here as patients acted as their own controls. Our normal range in 100 tests varied from a mean of $1.13 \mathrm{~g}$ at 21 to 30 years to $0.8 \mathrm{~g}$ at 61 to 70 years after two hours, and 1.97 to $1.56 \mathrm{~g}$ respectively at five hours after oral xylose (Kendall, 1970). After intravenous xylose the means were 1.93 and $1.41 \mathrm{~g}$, and 2.53 and $2.0 \mathrm{~g}$ respectively. Two-hour collections of urine really provide all the information and may be a better guide to absorptive efficiency (Kendall and Nutter, 1970).

The influence of drugs was assessed by comparing the excretion of xylose while taking the drug with the control value for that patient. Salicylate was given as four tablets of soluble aspirin $(1,200 \mathrm{mg})$ and indomethacin as four capsules $(100 \mathrm{mg})$. Each was taken with the oral xylose or 30 minutes before the intravenous dose. The differences in xylose excretion were analysed by Student's $t$ test. The changes in xylose excretion were also expressed as a percentage of the control value so that a mean percentage rise or fall was obtained.

The intravenous xylose test has been used to study the effect of drugs at sites other than the gastrointestinal tract. Though variation in metabolism could explain changes in xylose excretion, modification in renal function is more likely. 